\title{
CONHECIMENTO HISTÓRICO E CRIANÇAS PEQUENAS: PARQUES INFANTIS E ESCOLA MUNICIPAL DE EDUCAC̦ÃO INFANTIL
}

\begin{abstract}
Marcia Aparecida Gobbi*
RESUMO: Este artigo relata a experiência com o projeto "Os parques infantis de Mário de Andrade ontem e hoje", empreendido por todos os profissionais e crianças de uma escola municipal de Educação Infantil da cidade de São Paulo. A preocupação com o conhecimento histórico e as crianças da primeira infância e suas especificidades, numa perspectiva não-escolarizante e não-antecipatória do Ensino Fundamental, foi a tônica e um desafio. Procura aliar história e memória, estabelecendo relações entre História da Educação, história da escolarização de crianças pequenas e formação docente.

Palavras-chave: Educação Infantil. Parques Infantis. Conhecimento Histórico.
\end{abstract}

\section{HISTORICAL KNOWLEDGE AND SMALL CHILDREN: CHILDREN'S PLAYGROUNDS AND THE STATE'S PRIMARY EDUCATION}

ABSTRACT: This article discusses an experience with the project "The children's playgrounds of Mario de Andrade, yesterday and today", undertaken by all the professionals and children of a state primary school in the city of São Paulo. The concern with historical knowledge and the children in the first years of primary school, with their specific qualities, their un-schooled perspective and their inability to predict the school's teaching approach, was the keynote of this study and the challenge faced. A link between history and memory is sought, establishing a relationship between the History of Education, the history of small children being schooled and teacher training.

Keywords: Early Childhood Education. Playgrounds. Historical Knowledge.

* Doutora em Ciencias Sociais e Educação pela Universidade Estadual de Campinas (UNICAMP); Professora da Faculdade de Educação da Universidade de São Paulo (USP). E-mail: mgobbi@usp.br 


\section{Primeira infância e história}

_ O que aquelas crianças estão fazendo lá no parque? Faz um tempão que estão juntas, cavoucando aquela terra.

_ Professooora, olha o que eu achei!!

- Traz aqui para eu ver.

_ Mas são pedaços de azulejos que estão enterrados no chão. Por que tantos? Mas o que vocês vão fazer com isso?

Há poucos anos, no bairro da Lapa de Baixo, próximo à estação de trem da Lapa, zona oeste da cidade de São Paulo, algumas crianças frequentadoras da Escola Municipal de Educação Infantil Neyde Guzzi de Chiacchio', em suas constantes brincadeiras no parque pertencente à escola, encontraram pequenos fragmentos de azulejos brancos. Tal descoberta, um tanto inusitada, suscitou a curiosidade das professoras e dos demais funcionárias que trabalhavam na EMEI e de outras crianças que até então se encontravam envolvidas em afazeres variados, absortas em suas brincadeiras.

A descoberta dos caquinhos de azulejo enterrados nessa escola de Educação Infantil do município de São Paulo poderia não ter chamado a atenção de mais ninguém. Tantos são os acontecimentos no dia a dia da educação da primeira infância, em diversos municípios do país, que poderia ser compreendido como mais uma eventualidade a despertar o desejo de ver e ouvir algo insólito, por um breve espaço de tempo apenas, partindo, posteriormente, para outras atividades ou até mesmo sendo alvo de um desfecho rápido dado pela professora: joguemos tudo fora e vamos para a sala de aula.

Contudo, esses pequenos fragmentos de azulejos brancos despertaram a atenção para uma espécie de escavação feita pelos meninos e meninas, à época na faixa etária entre três e seis anos, numa das tardes de abril de 2005, na escola pública municipal, freqüentada, em sua maioria, por crianças oriundas de bairros distantes de onde está localizada a escola.

Esses cacos de azulejos, de diferentes tamanhos e bastante desgastados pelo tempo, começaram a chamar ainda mais a atenção quando se percebeu que havia muitos e muitos mais, despertando outras atividades entre as crianças: reunião de caquinhos que se tornavam bichos, bonequinhas, colocados em sequência, delineavam pistas onde carrinhos pas- 
savam, conduziam a água, que corria como num rio, enfim, um amplo e aparentemente inesgotável exercício de inventividade infantil.

Entre os adultos, evocavam o desejo de conhecer mais profundamente o que estava acontecendo - dia após dia, tais caquinhos multiplicavam-se nas mãos dos meninos e das meninas -, resultando numa movimentação entre as crianças que, além de suscitar curiosidade, apresentava evidências de um espaço diferente daquele, ocupado, em outro tempo, talvez, de maneira diversa da que hoje usualmente acontece.

Algumas das professoras já conheciam aspectos históricos do local onde trabalhavam, o que favoreceu um prévio estabelecimento de relações sobre a origem dos pequenos pedaços de azulejos concentrados na área externa. A escuta e os olhares mais atentos levaram a perceber, por outro lado, o interesse dos descobridores em sua escavação, uma espécie de atividade de arqueólogos encontrando estilhaços oriundos de um tempo remoto, a suscitar curiosidades. Curiosidade sobre o mundo é uma das mais importantes capacidades humanas: ela coloca-nos à frente, faz andar, move, permite a criação de projetos e a materialização dos mesmos, nos desloca naquilo que já temos como naturalizado pela cotidianidade, que, por vezes, sufoca, tira-nos o brilho e o desejo. Curiosices infantis, quando em ressonância com adultos e adultas, também em expansão inventiva pelo mundo, podem contribuir para a criação de grandes e proveitosos momentos de pesquisa, nos quais todos são considerados como importantes no caminho a ser seguido: adultos e crianças.

E foi assim - na descoberta de cacos de azulejos, num parque público de uma unidade escolar destinada à primeira infância, numa EMEI - que teve início, por parte de todo o corpo docente da escola, um intenso trabalho preocupado com o conhecimento histórico e a relação tão delicada com as crianças pequenas, para as quais o ensino de história não tem se debruçado de maneira bastante aprofundada, como requerem as pesquisas voltadas para essa faixa etária. Conforme Bittencourt (2007), muitas vezes prevalece a afirmação de que é bastante difícil a realização de um trabalho preocupado com o conhecimento histórico com as crianças pequenas, devido à sua incapacidade de compreensão dos conteúdos, assim como devido a uma incapacidade de abstração, o que impossibilitaria a compreensão do tempo histórico. Prevalece, muitas vezes, uma ideia de ensino de história que objetiva a memorização de conceitos ou fatos históricos, ignorando-se o percur- 
so pelo qual as crianças passarão quando diferentes experiências serão vividas.

Retomarei esse assunto mais adiante, contudo, sublinho, desde já, que não se trata de afirmar a impossibilidade de trabalhos na educação da primeira infância que considerem os estudos historiográficos, período no qual é também pertinente a preocupação dos pesquisadores voltados para o ensino de história. Cabe mencionar, que nessa faixa etária, embora possamos trabalhar com a noção de tempo e conhecimento histórico, as expectativas em relação aos resultados sofrem variações, ao mesmo tempo que não temos um ensino sistematizado, baseado em princípios próprios ao ensino fundamental, há especificidades dessa fase da vida que, obrigatoriamente, têm de ser consideradas: o corpo que necessita correr enquanto conversa com os colegas ou escuta a professora, resistindo a um modelo escolar que lhe impõe se sentar horas a fio; a imaginação e a fantasia, que levam as crianças a darem soluções, inimagináveis pelos adultos, a problemas de seu cotidiano; as emoções, que também são elementos que merecem consideração e permeiam o cotidiano de todos, compondo-o. $\mathrm{O}$ aprendizado dos mais diferentes campos de conhecimento ocorre espalhado na intensidade do cotidiano de creches e pré-escolas, cujo formato escolar, que divide o conhecimento em áreas que pouco ou nada dialogam, de caráter excessivamente escolarizante, privilegiando o trabalho individual em detrimento do coletivo, deforma ou constrange as ricas e vigorosas manifestações que se fazem sentir entre essas crianças pequenas, nos espaços coletivos de educação e cuidado.

A experiência descrita neste artigo, nas páginas iniciais, foi o mote para a criação coletiva de um projeto de estudos e pesquisas, nessa unidade escolar, voltado para o conhecimento da história da então Escola Municipal de Educação Infantil, conhecida desde 1935 como Parque Infantil da Lapa. Este artigo tem como objetivo relatar aspectos do projeto e alguns de seus desmembramentos, que se preocupou, a partir da história dos Parques Infantis, em recuperar partes da história da própria EMEI.

O projeto foi o ponto aglutinador de diversas discussões, que envolviam crianças e demais profissionais dessa unidade escolar, sobre a importância do conhecimento histórico junto às crianças pequenas - e a grande dificuldade de se realizar isso -, preocupando-se também com a constituição do pertencimento ao lugar, a construção de culturas infantis, 
debatidos e difundidos desde a criação dos Parques Infantis, bem como dar continuidade à construção da história pessoal das crianças, no contexto histórico, social, cultural em que estavam vivendo. Ressalto que essa experiência, junto com outras análogas realizadas em diferentes contextos, poderá contribuir com uma perspectiva de pesquisa na qual os conhecimentos históricos, em diálogo com os estudos sociológicos e antropológicos, possam ajudar a entender as infâncias nos diferentes contextos, assim como pensar no trabalho que considere os estudos preocupados com o ensino de história na relação com as crianças pequenas, sem ferir as especificidades da primeira infância, no que tange a construção de conhecimento, imaginação, fantasia, tão peculiares e fundamentais na primeira etapa da educação básica.

Espera-se aqui mostrar, ainda que brevemente, uma imagem orgânica e não exaustiva da experiência que reuniu crianças e adultos, de todos os segmentos pertencentes à EMEI Neide Guzzi de Chiacchio, o antigo Parque Infantil, no percurso de um projeto que optou por partir da escuta e da observação atentas daquilo que os meninos e meninas apresentavam como desejos e curiosidades, o que foi fundamental para o caminho seguido. A opção pelo trabalho com projetos de longa duração, definidor de percursos formativos de todos os envolvidos, deve-se ao reconhecimento da importância de as crianças construírem redes de significações. A perspectiva era o rompimento com abordagens que visam apenas ao reconhecimento de conteúdos e fatos históricos, que tantas vezes redundam em exercícios esvaziados de sentido para seus participantes. Partiu-se da consideração das crianças como autoras e inventivas.

Optou-se ainda pelo contato com as brincadeiras, danças e músicas e desenhos como manifestações artísticas a serem experimentadas por todos, as quais foram conhecidas a partir das fontes documentais encontradas pelas professoras e pelas crianças, na própria EMEI, em visitas ao Departamento do Patrimônio Histórico ou mesmo ao acervo da Cinemateca de São Paulo e ao Instituto de Estudos Brasileiros da USP. Trata-se de pautas musicais, desenhos de crianças criados entre os anos de 1935 a 1938 e fotografias de Benedito Junqueira Duarte reproduzidas do original, músicas da época e atuais, caderno de uma das professoras que atuou nos anos 1950. Ao longo do processo, aprendeu-se, entre outras coisas, que os estudos históricos e aqueles voltados para o ensino de história, ao valorizar o contato das crianças com fontes de pesquisa, favore- 
ce a construção do conhecimento histórico. Não se tratou de um projeto fechado e, sim, de algo que foi se construindo ao longo e a partir das curiosidades e descobertas das professoras e crianças, salientando que houve o privilégio de um envolvimento com os profissionais de todos os segmentos pertencentes a essa unidade educacional.

\section{0 projeto ou conhecendo história com meninas e meninos pequenos}

Preocupações frequentes entre as professoras voltavam-se para o compromisso com as singularidades da primeira infância e suas características nessa etapa da Educação Básica. Os desafios que se colocavam dirigiam-se para a natureza da história a ser abordada com as crianças bem pequenas, ao mesmo tempo em que se pensava no "como fazer" tal trabalho. Sabe-se, como afirma Bittencourt (2007), que o ensino da disciplina escolar História por vezes apresenta obstáculos, para alguns intransponíveis, entre as crianças nessa faixa etária, pois, segundo certa leitura piagetiana, tal perspectiva de trabalho é considerada impossível porque, entre as crianças nessa faixa etária, não haveria condições para o aprendizado de conceitos essenciais para o estudo da história e, particularmente, a noção de tempo histórico.

Essa constatação, em princípio, inviabilizaria qualquer trabalho de estudo e pesquisa com as crianças que visasse ao conhecimento histórico. Ainda mais, desconsidera meninos e meninas como sujeitos no processo de construção de conhecimentos e da própria história. Pode-se perceber tal perspectiva como reveladora de uma concepção de infância como "vaso vazio" (MOSS, 2003), a esperar os conhecimentos que seriam transmitidos pelos adultos, reconhecidos como os legítimos transmissores de saberes. Contudo, tal como nos apontam Corsaro (2009) e Florestan Fernandes (1946), o que temos é uma capacidade enorme de aprendizagens e construção de culturas infantis na relação entre os pares de idades iguais e diferentes, ou de vizinhança, que se constitui de maneiras diversas, variando de acordo com os contextos sociais, históricos, culturais e econômicos nos quais as crianças se encontram. Pode-se inferir que não se trata de termos conteúdos exclusivos somente para o Ensino Médio ou Fundamental, mas de nos preocuparmos com a maneira como as crianças são concebidas na relação com os diferentes campos do conhecimento. 
Merece ser sublinhado aqui que é resultado de múltiplas relações lógicas, afetivas, sensoriais, cognitivas, não sendo um conjunto estável, hierárquico, linear.

As professoras, junto às demais profissionais da unidade escolar, tiveram como preocupação não considerar como princípio a maturidade biológica das crianças, numa percepção etapista do desenvolvimento infantil, mas levar em conta aquilo que portavam como conhecimentos e experiências desde bem pequenas, antes de chegar à escola, e na relação com os outros, numa demonstração de respeito e reflexão profunda sobre aquilo que as crianças são: alguém que, apesar da pouca idade, possui experiências históricas que não podem ser desconsideradas nos planejamentos, na organização do espaço físico, na escolha de materiais utilizados, em práticas educacionais que prescindem de avaliações como modo de mensurar conteúdos e aprendizagens, ao mesmo tempo em que considera as crianças integralmente. A observação daquilo que as crianças desejavam e faziam, externado, de forma explícita ou não, era ponto fundamental para as professoras, servia como baliza a orientar o trabalho e, ainda mais importante, o processo, e não apenas seu resultado. Trata-se, como afirma Benzoni (2001, p. 47, Tradução minha),

De um instrumento funcional e privilegiado que pode ser considerado como formas de exploração dos contextos que deve ser utilizada na articulação dos projetos de pesquisa, colhendo de forma organizada os aspectos significativos de uma situação. É escolher que coisa observar, como observar e qual significado, quais valores atribuir às informações conquistadas.

Como já afirmado, o início desse projeto ocorreu quando as crianças foram descobrindo, aleatoriamente, fragmentos de azulejos no parque da EMEI, servindo para elas como objeto de brincadeiras. Os cacos de azulejo eram, evidentemente, objetos de cultura material que serviram como mediadores para as discussões com as crianças, dotados de memória histórica que eram, já que refletiam, em certa medida, o modo de pensar e agir na Educação Infantil de determinado período. Dessa forma, não se tratava apenas de "cacos", mas de elementos constituintes de ambientes de determinado grupo social. Essa descoberta, contudo, vem ao encontro de aspirações de algumas das professoras, já interessadas em conhecer mais e melhor a história da EMEI Neide Guzzi, desde sua idealização, por Mário de Andrade, e sua inauguração, em 1935, como 
Parque Infantil da Lapa. No desenvolvimento do projeto, preocupadas com a origem do Parque Infantil e suas transformações até a forma como se encontra hoje, voltou-se, entre outras questões, para a história da infância das crianças parqueanas de ontem e que constitui parte da história das atuais frequentadoras da EMEI. Foi mostrando, ao longo do tempo, um itinerário que se realizava na escola e assumia significados para os envolvidos, recordado, examinado, perscrutado, em suas mais diversas possibilidades, reconstituído e socializado entre todos. Ressalto que o projeto ganhava, cada vez mais, novas proporções e contribuições de lembranças e fontes documentais que colaboravam por instigar e justificar o próprio projeto.

A preocupação pedagógica aliada à construção do conhecimento histórico tornava concretamente visíveis, também pela documentação, fontes que, ao serem pesquisadas, revelavam aspectos dos Parques Infantis, bem como davam visibilidade ao processo pelo qual as crianças passavam. Utilizavam-se entrevistas com antigos alunos ${ }^{2}$, conversas livres com as crianças, fotografias tiradas em profusão, sendo utilizadas à época como chaves de conversa para se discutir o caminho seguido e, ao mesmo tempo, registrá-lo, e discussões a partir de reproduções de fotografias tiradas dos Parques Infantis pelo fotógrafo Benedito Junqueira Duarte. As documentações produzidas pelas crianças e recolhidas continuamente permitiam-lhes que tomassem contato com as próprias descobertas e conquistas, possibilitavam que se refletisse sobre o itinerário percorrido e o que estava por vir, garantindo, com isso, a tomada de posição, ao ter de decidir quais rumos tomar no âmbito das pesquisas que seriam empreendidas. Dessa maneira, a documentação histórica dialogava com a documentação pedagógica que ia se constituindo e se tornando representação de histórias construídas pelas professoras e pelas crianças.

Fotografias, músicas e caderno de anotações de uma ex-professora dos anos $1950^{3}$ constituíram-se como fontes inestimáveis para conduzir as pesquisas, suscitar curiosidades e garantir a existência do levantamento de cada vez mais hipóteses e confrontação com resultados, ainda que provisórios. Um verdadeiro clima de investigação que invadia a todos, sem exceção, considerando aqui a participação marcante dos profissionais operacionais que atendiam a escola. O fio condutor era acreditar que o essencial é dar relevância às experiências diretas de contato com a história dos Parques Infantis e, hoje, da EMEI, numa pers- 
pectiva de história do presente das crianças e adultos, por meio das discussões a partir das fontes e dos demais materiais encontrados, valorizando as propostas e iniciativas dos meninos e meninas, em conjugação com os encaminhamentos que também eram sugeridos pelas adultas que trabalhavam no local.

Os já mencionados fragmentos de azulejos encontrados no parque da EMEI serviram, portanto, como pistas a indiciar o que havia naquele espaço. Imbuídas do desejo de revolver aspectos daquela história e expô-la como fundamental, para que todos a conhecessem, as professoras mobilizadas também saíam em busca de onde provinham os vestígios. Com a observação das fotos, logo a incógnita sobre os fragmentos de azulejos fora decifrada. Mas de onde provinham mesmo? Os tais cacos começaram a mostrar o que havia restado da piscina ampla que ficava naquele espaço e que fora aterrada quando os Parques Infantis passaram a ser as atuais Escolas de Educação Infantil, ganhando uma fachada arquitetônica de caráter mais escolar, com salas de aula e diminuição dos espaços destinados à brincadeira.

O que nós mais gostava (sic) era da piscina. Ih! nós jogava tinta na água para ver ela mudar de cor. Nós aprontava com as professoras.

(Depoimento de um dos primeiros frequentadores do Parque Infantil da Lapa, coletado por Mayra Villela Galatti Ozzetti - diretora da EMEI)

Essa piscina era um lugar de práticas esportivas - o que era constante nos Parques Infantis -, mas, mais do que isso, como pode ser percebido pelo depoimento de um dos frequentadores, hoje já falecido, era um espaço de cultivo de brincadeiras e experiências variadas, de escapatórias das crianças e exposição de suas invenções. As fotografias encontradas pelas professoras demonstravam a presença das crianças de outrora usufruindo desse espaço, que, ao ser soterrado, foi subtraído dos atuais frequentadores como lugar de convivência, exploração e criação. Os cacos de azulejo, restos de piscina, evidenciavam uma preocupação com as crianças que contraria grande parte das concepções atuais sobre as crianças da primeira infância, provocaram que pensassem sobre o direito à brincadeira em outros ambientes, tais como a água, privilegiando descobertas variadas em, como chamados à época, tanques de vadiar, lugares em que o tempo acelerado fosse superado pelo tempo das descobertas, andando à toa... 
As crianças constantemente indignavam-se perguntando: se havia piscina, por que atualmente não existia mais? Esse questionamento frequente impunha às professoras que trabalhassem apontando para $\mathrm{o}$ processo de transformações históricas que teve como resultado uma alteração profunda no espaço físico da escola, o que remeteu a modificações nas práticas educativas, nas relações estabelecidas entre todos, no tempo dedicado às descobertas e brincadeiras. Os meninos e meninas, sem perceber, estavam debatendo os primeiros temas de natureza histórica. $\mathrm{O}$ passado - ao falarem de um tempo em que nem eram nascidos - estava presente nas perguntas e apontava para debates pertinentes sobre a atual constituição daquele lugar e das próprias crianças frequentadoras dessa escola de Educação Infantil. Tínhamos, partindo das meninas e meninos, uma espécie de reivindicação do tempo para os jogos e as diferentes possibilidades de criação, colocando-se, de forma indireta, contrárias à silenciosa e sistemática exclusão da dimensão do imprevisto, das descobertas, tão caras às crianças e que outrora se fazia mais frequente, num espaço maior e rico em atividades voltadas para seu crescimento.

\section{Entre as transformações históricas do Parque Infantil a EMEI Neide Guzzi}

Mas de onde estamos falando? A atual EMEI, local de partida do projeto voltado para o conhecimento histórico na primeira infância, foi um dos três primeiros Parques Infantis idealizados por Mário de Andrade e inaugurados no ano de 1935, na cidade de São Paulo, na gestão do prefeito Fábio Prado. Inicialmente, como já mencionado, foram criados três Parques Infantis: Ipiranga, D. Pedro e Lapa, este último situado no bairro da Lapa de Baixo, mantendo algumas características originais que convivem com uma organização espacial que se aproxima de um formato escolar, com salas de aula e corredores4.

Algumas indagações surgiram: quais aspectos desse Parque Infantil figurariam entre as crianças de outrora e que ainda se encontram presentes, quais as permanências? O que pode ser desvelado a partir das pistas encontradas pelas crianças? Quais avanços e recuos? Quais as rupturas e mudanças? Qual a contribuição das descobertas de crianças e adultos para o conhecimento histórico abordado na primeira infância, algo que exige refinada sensibilidade e conhecimento sobre as especificidades 
das crianças nessa faixa etária. É chegada a hora de nos atermos um pouco aos Parques Infantis criados por Mário de Andrade, que, em certa medida, constituíram-se no grande alicerce das descobertas de todos na atual EMEI e no projeto desenvolvido.

Os Parques Infantis, no período de 1935 - quando criados por Mário de Andrade -, constituíam-se como expressão do interesse em relação à infância filha do operariado paulistano, na faixa entre 3 e 12 anos de idade, para a qual eles eram destinados, e a educação extraescolar. As atividades voltavam-se para a integração do jogo, a cultura, a arte, o conhecimento do folclore nacional e a saúde das crianças frequentadoras, o que merece ser sublinhado. Inspirou fortemente o projeto com as crianças na EMEI, conduzindo abordagens diversas em que as manifestações artísticas faziam-se presentes de modo constante. Sublinhamos a importância do diálogo entre artes e estudos da história, nesse projeto, o que está para além dele quando tomamos contato com as pesquisas voltadas para a primeira infância e encontramos as afirmações de que as diferentes manifestações artísticas devem compor os espaços destinados à educação e ao cuidado das crianças pequenas.

Dança, música, pintura, escultura, brincadeiras entre adultas e crianças faziam-se presentes. As pesquisas de Mário de Andrade, como estudioso do folclore nacional, encontravam lugar privilegiado para se expandirem. No que toca às pesquisas folclóricas, todo o material recolhido por Mário de Andrade em sua viagem à Amazônia servia como base para dramatizações das crianças nos Parques Infantis, numa procura por tornar a cultura nacional, tão propalada pelos modernistas, conhecida, construída e praticada pelos meninos e meninas. Tinha-se, nesses espaços físicos propostos por Mário de Andrade, as artes como fios que conduziam as criações infantis, numa junção entre arte, educação e cultura, colocadas no dia a dia das crianças, originando-se ambientes próprios aos meninos e meninas, convivendo entre si, na mistura de diferentes faixas etárias.

Tal perspectiva, que remontava a setenta anos, era recobrada e problematizada pelas professoras décadas depois, não numa perspectiva de conservação da história, como se ela não fosse dinâmica. Essa dimensão folclórica tornou-se presente, no projeto, a partir do momento em que cópias de antigas partituras de músicas e uma pequena ópera popular, descoberta por Mário de Andrade em suas viagens, fora descoberta e 
abordada com as crianças. Vale citar que, inicialmente, o tipo de música não caiu imediatamente no gosto das crianças, que questionavam sobre o porquê de tamanha diferença sonora e musical, ao mesmo tempo que narizes eram franzidos e alguns saíam das salas onde se propunha a audição das canções.

Quanto aos Parques Infantis, percebe-se que se tratava de colocar à tona variadas provocações inovadoras, de modo a instigar a criação, a invenção, a expressão, a busca pelas soluções, que, de forma coletiva ou individual, se encontram apoiadas num território da infância e para a infância, no qual as culturas infantis sejam construídas e reconhecidas.

Uma questão, entre tantas, ressoava em meio às professoras: já pensou se pudéssemos encontrar partes dessas marcas documentadas atualmente por nós daqui há décadas, revelando aspectos de uma infância que, a cada nova olhadela, pode reviver em nós e contribuir com nossos conhecimentos sobre ela mesma? Não se trata de uma obsessão pela memória, mas de considerar sua importância, o que, de certa maneira, foi possibilitado pelas descobertas das próprias crianças. Como afirma Benzoni (2001, p. 54-55, Tradução minha), "trata-se de um trabalho que apresenta a possibilidade de manter os traços de um trabalho, de não perder o sentido e então conservar memórias de experiências". A memória, segundo essa autora, não é apenas uma recordação, mas algo que nos marca como experiência, marcando fortemente nossa identidade. Quem passa por essa experiência poderá, segundo a autora, por meio de documentações, reencontrá-la no tempo, revê-la a distância, de um modo crítico ou de uma nova angulação, de diversos pontos de vista mais amadurecidos.

Quando procuravam saber algo sobre os Parques Infantis e, em especial, o da Lapa, encontrava-se a perspectiva criativa de um trabalho institucional que, na expressão do Modernismo, mostrava-se na fusão entre suas preocupações estéticas e as ideológicas, que se configuraram no Departamento de Cultura do município de São Paulo e, sobretudo, nos Parques Infantis, o que permite a demonstração de que os princípios das propostas renovadoras do Modernismo brasileiro estivessem contemplados em sua forma de criar na administração pública. Essas faces tão fecundas permitem a realização de tantos estudos e enfoques variados. Devido a essa presença da face modernista nos Parques Infantis, vale estudar aquilo que pode colaborar com os avanços da Educação Infantil bra- 
sileira, atualmente. E daí tal percurso não apenas instigava as crianças, mas, de modo concomitante, incentivava as professoras que o compunham a pensar sua própria história docente, as crenças e os valores no campo educacional.

A frequência das crianças nos Parques Infantis, inicialmente, era livre, e aqueles que eram alunos dos Grupos Escolares - correspondentes às atuais escolas de Ensino Fundamental - poderiam participar das atividades, em horários alternados aos das aulas. Como afirma Faria (2002), trata-se das origens da rede pública de educação da primeira infância em São Paulo.

Como constam nas solicitações às instrutoras que trabalhavam diretamente com as crianças nos Parques Infantis, no Ato n. 1146 de 4/7/1936, propiciavam-se experiências de diferentes modalidades, provocando a compreensão da pertinência das atividades coletivas como forma de relação social, como construção desses sujeitos de pouca idade. Dessa forma, associando a prática da organização de clubes e jornais à das produções artísticas, em destaque a criação de desenhos - tal como ocorriam no cotidiano dos Parques Infantis -, o que temos é o rompimento com os princípios mais tradicionais de organização de espaço e abordagem curricular para a Educação Infantil e séries iniciais do Ensino Fundamental, abrindo-se para a cidade, que se urbanizava ao redor dos Parques Infantis. Tomar contato com as propostas apresentadas para a formação das instrutoras - professoras - que trabalhavam nos Parques Infantis resultou também em debates sobre a atual formação das docentes que trabalhavam com as crianças na EMEI. O que era proposto e permaneceu? Quais as mudanças? O que se podia aprender com as propostas anteriores e foi sofrendo transformações, ao longo das décadas, no que tange as expectativas docentes? Eram perguntas que conduziam conversas e leituras que formavam as professoras ao longo do projeto.

Mário de Andrade, apreensivo com os rumos da educação, de forma original percebia a necessidade de práticas educativas voltadas para as crianças de seu próprio tempo, num constante diálogo entre culturas, cidade e manifestações artísticas. Vale ressaltar que a perspectiva de um trabalho que conjugava artes, folclore e demais manifestações humanas inspirou sobremaneira a configuração da EMEI e das atividades realizadas atualmente.

Um dos aspectos debatidos procurava ressaltar algo já salientado décadas atrás. É possível inferir, a partir das exigências constantes do 
Artigo 207 do Ato n. 1146, de 4/7/1936, que se tratava de algo que contemplava certas experiências práticas entre aqueles que trabalhariam com as crianças, tais como "velar por ela" (criança) "sem lhe perturbar ou ameaçar a liberdade e a espontaneidade no brinquedo" ou mesmo "ensinar a prática de jogos infantis, participando das atividades lúdicas e recreativas". Nas atividades que ocorriam, eram privilegiados a dramatização de contos e histórias, a roda cantada, a modelagem, a marcenaria, o bailado, a música, sem esquecer a formação em curso Normal - extinto Magistério -, preferencialmente da Escola Normal Caetano de Campos. Entre o que fora compreendido com as propostas educacionais inovadoras dos Parques Infantis, encontravam-se as atividades lúdicas e algo que chamou a atenção em extensas e profícuas discussões entre as professoras: Mário de Andrade, nas solicitações que fazia às instrutoras, pedia-lhes que não fizessem anotações nos desenhos das crianças, afirmando tratar-se de uma intervenção nas criações infantis. Curioso foi que as professoras perceberam-se, até hoje, com a permanência dessa prática e discutiam sobre o porquê de ela permanecer, por que escrever sem a autorização da criança, entre outros aspectos.

As práticas educativas tinham continuidade também nas pequenas exposições organizadas no interior dos Parques Infantis - registradas nas fotos de Benedito Junqueira Duarte -, trazendo a perspectiva de um ambiente-memória, que, embora não tivesse como preocupação central os resultados do que fora produzido, trazia a possibilidade de que aqueles que circulassem nos Parques Infantis entrassem em contato com o que era produzido lá dentro, valorizando-o, questionando-o, observando e aprendendo com as marcas deixadas pelas crianças suas frequentadoras. Tratase de documentar não somente os resultados, mas os processos. Com isso, narrava-se o que passou, de maneira composta por escritos, imagens, objetos, que revelam a presença das crianças também em sua ausência.

Tais exposições ganharam um grande espaço também na EMEI, quando se procurava não espetacularizar as criações infantis, mas destinar um tempo maior para observá-las e conhecê-las e, com isso, aprender sobre a própria infância. 


\section{Nos Parques Infantis e na EMEl: os desenhos como documentos históricos e expressão infantil}

Uma das atividades frequentes nas escolas de Educação Infantil é a criação de desenhos. Contudo, no desenvolvimento desse projeto, tal prática corriqueira ganhou outros ares, inspirados pela própria história com a qual todos vinham tomando contato. Trata-se do trabalho com desenhos a partir de conversas e de relações estabelecidas entre aqueles criados pelas crianças entre os anos de 1935 e 1938 e os desenhos de agora, dos meninos e meninas frequentadores da EMEI.

Mário de Andrade, numa de suas faces pouco exploradas, exibia interesse pelas criações em desenho de crianças e jovens, colecionando-os e refletindo profundamente sobre essa manifestação infantil. O conhecimento disso gerou buscas por conhecer seu pensamento sobre o assunto.

$\mathrm{Na}$ concepção de Mário de Andrade sobre a criança, nada melhor do que colocar em público o que elas criavam, guardar para observar, para serem vistas como construtoras, e não apenas como consumidoras de cultura: os desenhos poderiam saltar os muros das escolas, adentrando os bairros, a cidade, tornando-se visíveis a todos os que quisessem apreciá-los, fora de um espaço escolar que tantas vezes resvala numa perspectiva de confinamento. Essa experiência foi proposta na criação do mural que fica na parte externa da EMEI. Os desenhos criados pelas crianças eram reproduzidos e recriados nos azulejos e lá se encontram até hoje. Sua importância, entre outras coisas, encontra ressonância na proposta de documentar a presença e as marcas deixadas pelas crianças pequenas na história, o que, como sabemos, não se vê ou mesmo não se considera.

Entre os desenhos criados nos Parques Infantis e mostrados às crianças, os assuntos muitas vezes se repetiam. As flores aparecem com certa recorrência e apresentam, como característica mais frequente, galhos finos. Segundo observações de Mário de Andrade sobre esse conjunto de desenhos: "flores e frutos são da quase exclusiva preferência das meninas, como assunto. Não apareceu um só caso de flores isoladas, desenhadas por rapazes. As próprias frutas comestíveis raro os rapazes as representam isoladamente. Em geral, só as representam como complemento de árvores" (1966). É interessante nos atermos a um dos desenhos, representativo dos demais, e pensarmos nas transformações de temáticas, traços, 
formas e cores presentes nos desenhos atuais. Essa preocupação ocupou parte do projeto desenvolvido na EMEI, quando uma das professoras ocupou-se de mostrar às crianças o que e como os primeiros frequentadores do antigo Parque Infantil da Lapa criavam seus desenhos.

A inscrição: "foi respeitada a expressão da criança quando disse o que fez", encontrada no verso dos desenhos, prepondera nos trabalhos feitos por crianças de até seis anos, o que nos permite pensar numa atenção maior em relação à sua expressão, considerada "mais livre", numa atitude de valorização estética da produção e, consequentemente, da própria infância dos desenhistas.

\section{6. Últimas palavras, por enquanto...}

Neste artigo, procurou-se apresentar elementos de um projeto desenvolvido na Escola Municipal de Educação Infantil Neide Guzzi de Chiacchio, que objetivou também trabalhar com o conhecimento histórico entre as crianças pequenas. Como já mencionado, tratou-se de um grande desafio. Algo que foi aprendido no percurso desse projeto foi alimentar-se das próprias propostas que iniciaram os Parques Infantis, sem, contudo, colocá-las em lugar inquestionável, cristalizado ou mesmo comparando-o com o que ocorreu décadas atrás. Aquilo que permaneceu nas atuais propostas, inclusive educacionais, mais amplas era problematizado, num processo de intensa ruptura com o passado, numa compreensão de que este não se resume a apenas alguns fatos eleitos como oficiais. Em poucas palavras, ele servia para pensar o presente junto às crianças.

A valorização da criança foi uma constante e sempre passível de reflexões. Com isso, suas criações foram potencializadas, a imaginação e a invenção tornaram-se presentes a cada dia, provocando uma apreciação estética do mundo, que é também criado e recriado pelas crianças, para as crianças e com elas. Aproveitando-se dessa premissa, as professoras da EMEI foram percebendo, nas descobertas feitas pelas crianças, um grande motivador para o início do percurso e encontros do conhecimento histórico junto às crianças pequenas.

Tanto no projeto da escola, voltado também ao conhecimento histórico, quanto nas propostas dos Parques Infantis, o desenho, a brincadeira, todas as formas de expressão das crianças tornaram-se presentes de 
forma incisiva, proporcionando que o prazer das descobertas, das elaborações, estivesse presente e se constituísse em práticas junto às crianças que não engessassem a todos, adultos e crianças, ao transformar seu cotidiano em antecipação da escolarização, gradeado por muros invisíveis, que se tornam tão claros quando percebemos o conhecimento fragmentar-se em áreas que pouco ou nada dialogam entre si. As marcas da ansiedade pelo amanhã mostram-se quando, no dia a dia das crianças pequenas, somente há espaço para o desenvolvimento de atividades já preparadas ou "pré-paradas"? - que consistem em, ano após ano, desenvolver-se do simples ao mais complexo, do pequeno ao grande, do concreto ao abstrato, revelando que cada fase da vida da criança na escola está em função dos momentos sucessivos e da superação das passagens previstas, atingindo graus mais elevados, desconsiderando a própria criança. Como afirmará Staccioli (2002, p. 5),

Deve-se substituir a ânsia pelo amanhã pela riqueza do hoje, acolhendo o presente (com todas as surpresas, contradições que ele comporta) sem deixar de traçar o futuro; olhar para a infância agora e não como algo que dará frutos amanhã; observar suas capacidades de inovar que enriquecem também aos adultos.

Não se trata de deixar de lado aspectos relacionados com as áreas de conhecimento que serão trabalhadas no interior das escolas de Educação Infantil. Essa preocupação demanda que os olhares estejam atentos, sejam problematizadores, capazes para colher, no que está explícito e também implícito, nas crianças, informações para construir uma jornada de trabalho coerente, para organizar melhor o espaço e o tempo, dando forma às criações, à exuberância das crianças, de seus projetos, considerando sua diversidade e, como disse Kuhlmann Jr., "praticando orientações curriculares que estejam pautadas pela simplicidade, no lugar de formular uma complexidade simplista" (1999, p. 58).

Daí, o fato de estar com as crianças e aprender com elas a partir delas mesmas tornar-se fundamental. A especificidade dessa profissão reside nisso e na necessidade de pesquisa constante sobre as crianças e suas emoções, desejos por saber ou não. Para tanto, aliar os campos teóricos - quais os conhecimentos que foram e que estão sendo produzidos sobre a criança e as áreas que a estudam - aos campos da prática educativa é fundamental. Citando Kuhlmann Jr (1999, p. 65): 
Mas tomar a criança como ponto de partida exigiria compreender que para ela conhecer o mundo envolve o afeto, o prazer e o desprazer, a fantasia, o brincar e o movimento, a poesia, as ciências, as artes plásticas e dramáticas, a linguagem, a música e a matemática. Que para ela a brincadeira é uma forma de linguagem e a linguagem uma forma de brincadeira.

Retomando a citação inicial deste artigo, a grande vantagem neste estudo de história reside na possibilidade de compreender, de modo mais articulado, o que aconteceu até chegarmos onde nos encontramos. Procurou-se realizar isso com as crianças bem pequenas, uma tarefa árdua, desafiadora e não menos importante na constituição desses meninos e meninas e, por que não, dos profissionais envolvidos. Sabendo não se poder voltar mais atrás, transformando os Parques num lugar idílico para a infância, pode-se, com isso, construir projetos outros que estão ainda se desmembrando em festas, estudos, vídeos e em novas pesquisas. Não se tratou aqui de voltar-se para uma história factual, preocupada com o estudo, já tão debatido, sobre o chamado patrono da escola, mas, sim, de se questionar, a partir da própria unidade escolar voltada para a educação da primeira infância, quais as possibilidades de trabalhar com o conhecimento histórico junto às crianças tão pequenas, uma das questões que iam surgindo e se fazendo na construção do próprio projeto, ao mesmo tempo que os conhecimentos já acumulados sobre a primeira infância, a partir de inúmeros trabalhos e leituras realizadas, dialogavam, constantemente, numa atitude vigorosa. 


\section{Referências}

ANDRADE, Mário de. Aspectos das artes plásticas no Brasil. São Paulo: Martins Fontes, 1967.

ANDRADE, Mário de. Depoimentos 2 - publicação periódica para debate de arquitetura Centro de Estudos Brasileiros/ GFAU, s/d [mimeo].

ANDRADE, Mário de. Será o Benedito? Crônicas do suplemento em retrogravura do Estado de São Paulo. São Paulo: EDUC, 1992.

ANDRADE, Mário de. Táxi e crônicas do diário nacional. São Paulo: Livraria duas Cidades, 1976.

ANDRADE, Mário de. A escrava que não é Isaura. In: ANDRADE, Mário de. Obra imatura. São Paulo: Martins Fontes, 1986. p. 201-297.

ANDRADE, Mário de. O baile das quatro artes. São Paulo: Martins Fontes, 1975.

ANDRADE, Mário de. Quatro pessoas. Belo Horizonte: Itatiaia, 1985.

ANDRADE, Mário de. Do Desenho. In: ANDRADE, Mário de. O desenho de Lasar Segall. São Paulo: Museu Lasar Segall, 1991.

ANDRADE, Mário de. Cartas a Murilo Miranda (1934-1945). São Paulo: Nova Fronteira, 1988.

ANDRADE, Mário de. Cartas a Oneyda Alvarenga. São Paulo: Duas Cidades, 1982.

ANDRADE, Mário de. Cartas de trabalho: correspondência com Rodrigo Mello Franco (1936-1945). Brasília: MEC/SPHAN, 1981.

ANDRADE, Mário de. Pintura e Assunto. O Estado de S.Paulo. 13/4/41. In: MAC-IEB, Catálogo da Exposição comemorativa dos 25 anos do MAC e do IEB,1988.

ANDRADE, Mário de. As escapatórias do Amor. O Estado de S.Paulo. 16/4/41. In: MAC-IEB. Catálogo da exposição comemorativa dos 25 anos do MAC e do IEB, 1988. ANDRADE, Mário de. Cai, cai, balão. In: ANDRADE, Mário de. Os filhos da Candinha. São Paulo: Martins Fontes, 1963. p. 123-126.

ANDRADE, Mário de. $\sigma^{\mathrm{a}}$ aula. O primitivo e a criança. Centro de Estudos Brasileiros. Depoimentos. p 67-76, 1966.

ANDRADE, Mário de. Divina Preguiça. In: ROSSETTI BATISTA et al. Brasil, primeiro tempo modernista. 1917-1919. São Paulo: IEB, 1972. p. 181-183.

ANDRADE, Mário de. Uma grande inocência. In: ANDRADE, Mário de. O empalhador de passarinhos. São Paulo: Martins Fontes, 1972.

ANDRADE, Mário de. Piá, não sofre, sofre? In: ANDRADE, Mário de. Os Contos de Belazarte. São Paulo: Martins Fontes, 1939.

ANDRADE, Mário de. Tempo de Camisolinha. In: ANDRADE, Mário de. Contos Novos. São Paulo: Martins Fontes, 1939.

ANDRADE, Mário de. Primeiro de maio. In: ANDRADE, Mário de. Contos Novos. São Paulo: Martins Fontes, 1939.

ANDRADE, Mário de. O pai do gênio. In: ANCONA LOPEZ (Org.) Táxi e crônicas no Diário Nacional. São Paulo: Duas cidades, 1976. p. 276-279.

ANDRADE, Mário de. Da criança prodígio I e II. In: ANCONA LOPEZ (Org.) Táxi e crônicas no Diário Nacional. São Paulo: Duas cidades, 1976. p. 129-134.

ANDRADE, Mário de. Da criança prodígio III. In: ANCONA LOPEZ (Org.) Táxi e crônicas no Diário Nacional. São Paulo: Duas Cidades, 1976. p. 137-138. 
ANDRADE, Mário de. Pintura Infantil. In: ANCONA LOPEZ (Org.) Táxi e crônicas no Diário Nacional. São Paulo: Duas cidades, 1976. p. 277-279.

ANDRADE, Mário de. Do desenho. In: ANDRADE, Mário de. Aspectos das artes plásticas no Brasil. Belo Horizonte: Itatiaia, 1975. p. 71-77.

ANDRADE, Mário de. Da criança prodígio III. In: ANCONA LOPEZ (Org.) Táxi e crônicas no Diário Nacional. São Paulo: Duas cidades, 1976. p. 277-279.

ANDRADE, Mário de. O movimento modernista. In: ANDRADE, Mário de. Aspectos da literatura brasileira. São Paulo: Martins Fontes, 1974.

BECCHI, Egle. Por uma pedagogia do bom gosto. In: BECCHI, Egle. Avaliando a préescola: uma trajetória de formação de professoras. São Paulo: Autores Associados, 2003. BENZONI, Isabela. Documentare? Si, grazie. Bologna. Itália: Junior, 2001.

BENJAMIN, Walter. Obras escolhidas: magia e técnica, arte e política. São Paulo: Brasiliense, 1993.

BITTERCOURT, Circe. Fundamentos do ensino de História. São Paulo: Cortez, 2007.

CARUSO, Carla; BONITO, Ângelo. Anita Malfatti: crianças famosas. São Paulo: Callis, 2002.

CORSARO, William. Reprodução interpretativa e cultura de pares. In: MULLER, Fernanda (Org.) Teoria e prática na pesquisa com crianças: diálogos com William Corsaro. São Paulo: Cortez, 2009.

DEPARTAMENTO DE CULTURA. Regimento interno dos Parques Infantis. S/d.

FERNANDES, Florestan. A cultura infantil. In: FERNANDES, Florestan. Folclore e mudança social na cidade de São Paulo. Rio de Janeiro: Vozes, 1979.

GALLARDINI, Annalia. Casa, scuola, museo: familiaritá, dissonanza nell'esperienza dei bambini. In: GALLARDINI, Annalia. Il Bambino con arte nell museo. Comune di Pistóia: Junior, 2002. p. 19-29.

GINSZBURG, Carlo. Mitos, emblemas e sinais: morfologia e história. São Paulo: Companhia das Letras, 2001.

GOBBI, M.; LEITE, Maria I. O desenho da criança pequena: distintas abordagens na produção acadêmica em diálogo com a educação. In: LEITE, Maria Isabel (Org.) Ata e desata. Partilhando uma experiência de formação continuada. Rio de Janeiro: Ravil, 2002. p. $93-148$.

GOBBI, Marcia A. Lápis vermelho é de mulherz̨inha: desenho infantil, relações de gênero e educação infantil. Dissertação (Mestrado). Unicamp, Faculdade de Educação, 1997.

GOBBI, Marcia A. Desenho infantil e oralidade: instrumentos de pesquisa com crianças pequenas. In: DEMARTINI, Z.; PRADO, P. D.; FARIA. A. L. (Orgs.) Por uma Cultura da Infância: por uma metodologia de pesquisa com crianças. Campinas: Autores Associados, 2002.

GOBBI, Marcia A. Crianças nos parques: imagens de infância. Revista Pro-posições, v. 13, n. 2 (38), p. 143-159 maio/ago. 2002.

KOSSOVITCH, Elisa Angotti. Mário de Andrade plural. 2 ed. Campinas: Unicamp, 1990. KUHLMANN Jr., Moyses. Instituições pré-escolares assistencialistas no Brasil (18991922). Cadernos de Pesquisa, São Paulo, n. 78, p. 17-26, 1991.

MAVIGLIA, Mario; ZUNINO, Giovanna. Comunicaz̨ione gráfico-pittorica: itinerari didattici di espressione e creativitá com messaggi, forme e media. Bologna: Junior, 2002.

MIGNOLA, Luciana. La ompostazione della ricerca. In: MIGNOLA, Luciana. 
Documentare? Sì, grazie. Bologna: Junior, 2001.

MAC-USP/ IEB-USP. Mário de Andrade e a criança. In: BARBOSA, A . M. Leituras no sub-solo. São Paulo: Cortez, 1997.

MALLAGUZZI, Loris. Entrevista dada a Giordana Rabitti. In: RABITTTI, Giordana. Em busca da dimensão perdida. São Paulo: Artmed, 1999.

MALLAGUZZI, Loris. Apresentação. In: MALLAGUZZI, Loris. I picolissimi Del cinema muto. Giochi di finsioni al nido fra pesci e Bambini. Comune de Reggio, 1996.

MANTOVANI, Suzanna (Org.) Nostalgia do futuro: liberare speranze per uma nuova cultura dell'infanzia. Bergamo: Junior, 1998.

MARIN, Louis. Ler um quadro. Uma carta de Poussin em 1639. In: CHARTIER, Roger (Org.). Práticas da leitura. São Paulo: Liberdade, 1996.

MARTINS, Mirian C. F. Dias. Não sei desenhar. Dissertação (Mestrado). São Paulo, USPECA,1992.

MOSS, Peter. Qualidade na educação da primeira infância. Porto Alegre: Artmed, 2003.

FARIA, A. L.; DEMARTINI, Z.; PRADO, P. D. (Orgs.) Por uma Cultura da Infância: por uma metodologia de pesquisa com crianças. Campinas: Autores Associados, 2002.

PREFEITURA MUNICIPAL DE SÃO PAULO. A visão dos educandos. Movimento de reorientação curricular, 1993.

RABBIT'T, Giordana. Em busca da dimensão perdida. Porto Alegre: Artmed, 1999.

READ, Herbert. O sentido da arte. São Paulo: Ibrasa, 1976.

READ, Herbert. A redenção do robo: meu encontro com a educação através da arte. São Paulo: Summus, 1986.

SCUOLA GIROTONDO. Scuola comunalle Dell'infanzia Gulliver. Uguali i diversi:lêdiferenze sessuali nei pensieri dei bambini. Reggio-Emilia, 1990/91.

STACCIOLI, Gianfranco. Immagine fatte ad arte: idée ed esperienze per educare alla comunicazione visiva. Roma: Carocci, 2002.

STACCIOLI, Gianfranco. Disegnare per crescere. Bambini, Anno XII, n. 0, Bergamo, Edizione Junior, nov. 1996.

STACCIOLI, Gianfranco. Per uma educazione artística di senso. In: STACCIOLI, Gianfranco. Il Bambino com Arte nel museo. Comune di Pistoia: Junior, 2002. 


\section{Notas}

1 As Escolas Municipais de Educação Infantil de São Paulo são comumente conhecidas pela sigla EMEI, que será utilizada por mim neste artigo. As EMEIs são destinadas à educação e ao cuidado de crianças em idade entre três e cinco anos de idade, já que aos seis, atualmente, começam a frequentar as escolas de nível fundamental. Agradeço especialmente à diretora da EMEI Mayra Galatti Ozzetti e professoras.

2 Nos limites deste artigo, essas entrevistas não serão privilegiadas, contudo, ressalto o trabalho rigoroso realizado por Mayra Villella Gallatti Ozzetti, diretora da EMEI, de coleta de entrevistas, as quais, posteriormente, foram compiladas em vídeo. Vale ressaltar que, durante a pesquisa, a aluna "número um" matriculada no Parque Infantil da Lapa foi encontrada e participou de alguns encontros e festejos que ocorreram na EMEI, ao longo desse ano.

3 Interessante observar que se os demais achados mobilizavam descobertas entre as crianças, o caderno da antiga professora foi um importante incentivador das professoras à época, para que elas refletissem e investigassem suas práticas educativas atuais em relação àquelas desenvolvidas décadas atrás, envolvendo formas de anotação, atividades propostas, forma de escrita e até mesmo a maneira de organizar o caderno e os registros.

4 A sensibilidade de Mário de Andrade para com a infância se coaduna à expressão de uma estética modernista que, entre outras, apresenta a temática da infância de modo genuíno. Tal interesse foi manifestado também em artigos publicados no Diário Nacional, onde colaborou como cronista e crítico de arte até o jornal ser fechado, em 1932. Tais como Pintura Infantil (1930), Da criança prodígio I, II e III (1929), entre outros, esses textos foram reunidos no livro Táxi: Crônicas no Diário Nacional. É perceptível, neles, o delineamento do conceito da criança como portadora de culturas, cidadã, múltipla em suas diversas possibilidades de criação e presença nos diferentes espaços e relações sociais, destacando-se a discussão sobre arte e infância.

Recebido: 24/03/2011

Aprovado: 27/09/2011

Contato:

Faculdade de Educação da Universidade de São Paulo

Avenida da Universidade, 308

Cidade Universitária

CEP 05508-040

São Paulo, SP

Brasil 